\title{
Synchronized roles of pannexin and connexin in nasal mucosal epithelia
}

\author{
Toyoaki Ohbuchi ${ }^{1}$ (1) $\cdot$ Hideaki Suzuki ${ }^{1}$
}

Received: 21 February 2018 / Accepted: 20 March 2018 / Published online: 24 March 2018

(c) The Author(s) 2018

\begin{abstract}
Background Nasal mucosal epithelial cells express connexins, the prototypical gap junction proteins, and pannexins, a new family of channel proteins homologous to the invertebrate gap junction proteins. The physiological and pathophysiological roles of these transmembrane proteins in nasal mucosa are largely still unknown.

Purpose Pannexins participate in ATP release into the extracellular space in various tissues, and ATP plays important roles in mucociliary clearance, especially by regulating ciliary beat activity. Therefore, we focused on the functional relationship between connexins, pannexin-1, ATP release, and mucociliary clearance in nasal epithelia.

Results and Conclusions Connexins participate in the generation of intercellular calcium waves, in which calcium-mediated signaling responses spread to contiguous cells through the gap junction formed by connexins to transmit calcium signaling throughout the airway epithelium. Pannexins in the nasal mucosa may contribute to not only ciliary beat modulation via ATP release, but also regulation of mucus blanket components via $\mathrm{H}_{2} \mathrm{O}$ efflux. The synchronized roles of pannexin and connexin may provide a new insight into effective mucociliary clearance systems in nasal mucosa.
\end{abstract}

Keywords ATP release $\cdot$ Ciliary beat frequency $\cdot$ Connexin $\cdot$ Gap junction $\cdot$ Mucociliary clearance $\cdot$ Mucus blanket $\cdot$ Nasal mucosal epithelia $\cdot$ Pannexin-1

\section{Abbreviations \\ MCC Mucociliary clearance \\ CBF Ciliary beat frequency \\ CRS Chronic rhinosinusitis \\ CBX Carbenoxolone \\ OML Outer mucus layer \\ PCFL Periciliary fluid layer}

In the upper airway, mucociliary clearance (MCC) serves to remove inhaled particulate matter along with secreted mucus, and thereby contributes to host defense mechanisms. MCC is regulated by appropriate levels of mucus production and ciliary activity, which is usually measured by ciliary beat frequency (CBF). In the nose, mucociliary dysfunction can be a significant clinical problem, and has been reported

Toyoaki Ohbuchi

oh-buchi@med.uoeh-u.ac.jp

1 Department of Otorhinolaryngology-Head and Neck Surgery, School of Medicine, University of Occupational and Environmental Health, 1-1 Iseigaoka, Yahatanishi-ku, Kitakyushu 807-8555, Japan to occur in patients with various inflammatory diseases including chronic rhinosinusitis (CRS) [1].

The connexin proteins form hemichannels that dock to form gap junctions, which are intercellular communication channels [2]. These junctions mediate electrical and biochemical communication between a wide variety of somatic cells and tissues [2]. There are 21 connexin subtypes that have been identified in humans. A recent report revealed that 16 connexin genes are expressed in the human sinus mucosa [3]. One report found that connexin-43 is significantly upregulated in CRS patients compared to healthy controls at both the mRNA and protein levels, whereas other reports searching for a potential cause of dysfunction in the sinonasal epithelium failed to find a significant difference in the expressions of connexin-26, -30, -32, or -43 [3-5]. Although the relationship between CRS and connexin expression is still controversial, those reports have consistently shown that connexin-43 is expressed in human nasal epithelial cells. Connexin-43 is also expressed in rat nasal epithelia [6].

An intracellular response to calcium influx in nasal mucosal cells induces an increase in CBF and triggers a calcium wave that spreads to neighboring cells through the gap junction channels, such as those containing connexin- 43 . 
This wave elicits a calcium influx reaction in these neighboring cells via the same mechanism, leading to the transmission of calcium signaling throughout the airway epithelium [7, 8]. Many chemical stimuli can initiate this calcium signal. For example, extracellular ATP is a key modulator of CBF through the activation of purinergic receptors, which leads to calcium influx in the epithelial cell $[1,9,10]$.

ATP is thought to be released into the extracellular space via two distinct pathways: vesicular- and channel-mediated release pathways. Among the many channel-mediated pathways, the pannexin channel is considered a promising candidate mediator of ATP release. Pannexins are a family of transmembrane channel proteins in vertebrates comprising three subtypes: pannexin-1, pannexin-2, and pannexin-3 [11]. Pannexins are homologous to innexins, the invertebrate gap junction proteins, and thus were originally cloned as gap junction-related proteins; however, they do not appear to play a role as gap junction proteins in vivo so far [11-14]. Consistent with these findings, the pannexins have no significant sequence similarity to connexins [15].

The pannexin- 1 channel forms a homohexameric largeconductance nonselective channel that participates in ATP release into the extracellular space [12, 16-18]. Recently, we have provided evidence of pannexin- 1 expression in, and ATP release from, rat and human nasal mucosa [19-22]. The pannexin-1 channel can be activated in either a calciumdependent or, interestingly, calcium-independent manner. In calcium-dependent activation, pannexin- 1 channel opening is evoked by signal transduction events following the activation of the ionotropic purinergic $\mathrm{P} 2 \times 7$ receptor, which is directly coupled with the pannexin- 1 channel $[12,16$, 23]. Activation of the acetylcholine receptor and transient receptor potential vanilloid 1 (TRPV1) also induces ATP release by pannexin- 1 in nasal mucosa $[21,22]$. In calciumindependent activation, the pannexin- 1 channel is triggered by mechanical stimulation, such as hypotonic stress-induced cell swelling and membrane stretching [2, 13, 20, 24-26].

The role of pannexin-dependent ATP release in the nasal mucosa is still a matter of debate. The mucus blanket is divided into a gel-like outer mucus layer (OML) and a liquid periciliary fluid layer (PCFL) [27]. The mucus of the OML is produced and secreted by goblet cells and submucosal glands. The fluid of the PCFL is maintained by $\mathrm{H}_{2} \mathrm{O}$ balance as well as an equilibrium between anion efflux and cation influx through the epithelial cell membrane. If the volume of the PCFL is reduced, ciliary movement becomes inefficient because of increased contact between the cilia and the viscous OML. Conversely, when the volume of the PCFL increases beyond its normal volume, ciliary movement also becomes inefficient because the cilia cannot reach the OML to stimulate it. Therefore, PCFL volume is extremely important for ensuring functional MCC.

These facts led us to hypothesize that pannexindependent ATP release may, in part, constitute a $\mathrm{H}_{2} \mathrm{O}$ homeostasis system for maintaining the appropriate PCFL volume. To address this hypothesis, we examined whether

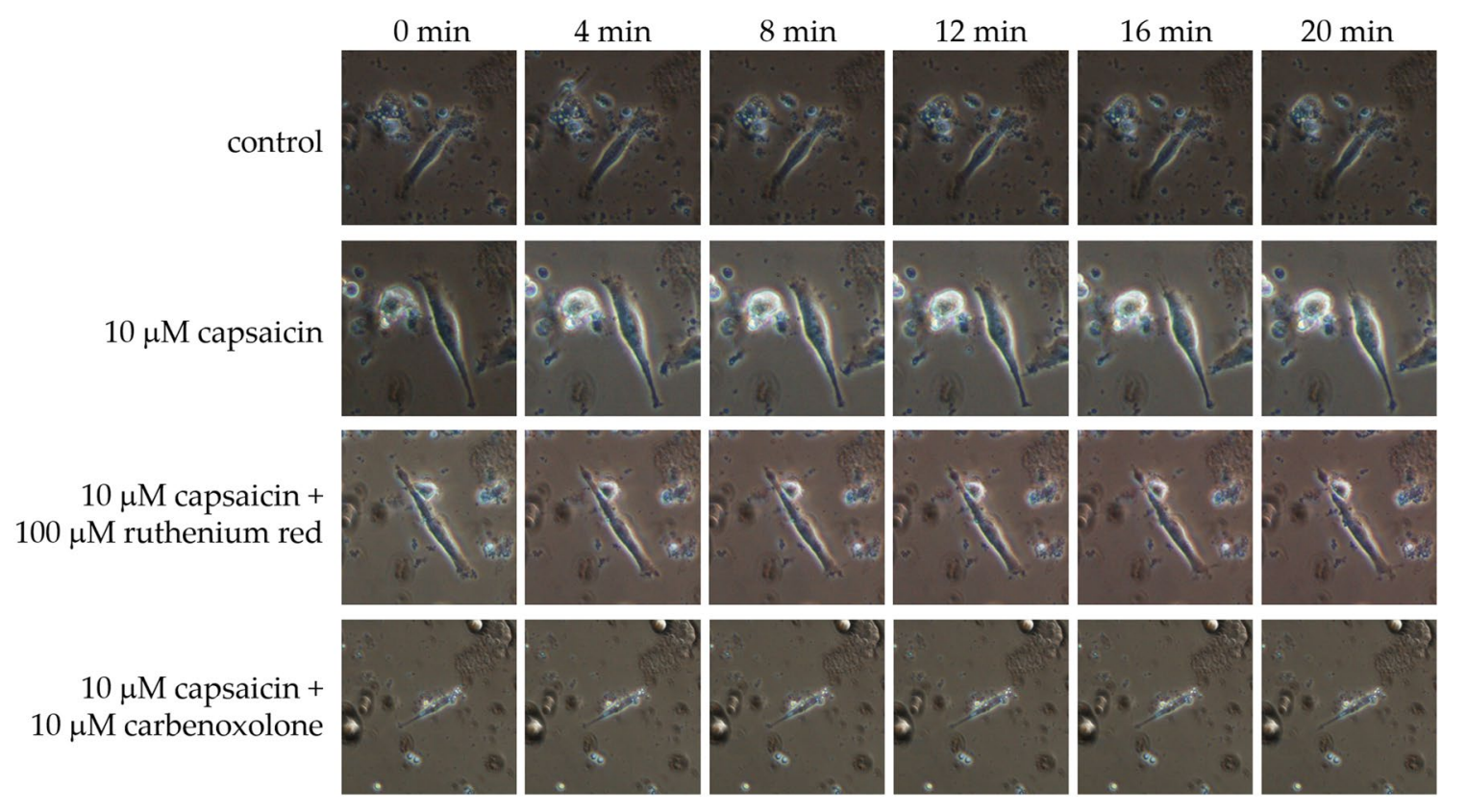

Fig. 1 Representative dissociated rat nasal columnar epithelial cells under a phase-contrast microscope with the indicated treatments. Photographs were captured every $4 \mathrm{~min}$ from $0 \mathrm{~min}$ (baseline) to $20 \mathrm{~min}$. The cell shape did not change in the control cells $(n=2)$,

and application of $10 \mu \mathrm{M}$ capsaicin led the apical side of the cells to shrink over the observation period $(n=3)$. This capsaicin-induced local shrinkage was inhibited by co-treatment with either $100 \mu \mathrm{M}$ ruthenium red $(n=2)$ or $10 \mu \mathrm{M}$ carbenoxolone $(n=2)$ 
pannexin-1 channels on nasal columnar epithelial cells contribute to $\mathrm{H}_{2} \mathrm{O}$ efflux. Our recent studies showed that TRPV1-associated, capsaicin-induced ATP release thorough pannexin-1 regulates ciliary beat activity in rat nasal mucosa [22]. Therefore, we used individual rat columnar cells in this study, which were enzymatically dissociated from the nasal mucosa. We used $10 \mu \mathrm{M}$ capsaicin as a TRPV1 agonist, $100 \mu \mathrm{M}$ ruthenium red as a TRPV1 antagonist, and $10 \mu \mathrm{M}$ carbenoxolone (CBX) as a pannexin-1 channel antagonist. We expect that connexin hemichannels, likely those containing connexin-43, are expressed in the single nasal epithelial cells. However, $10 \mu \mathrm{M}$ CBX is considered insufficient to block connexin hemichannels [28, 29].

Application of capsaicin led to shrinking of the columnar epithelial cells. Interestingly, this shrinking occurred only at the apical side but not the basal side. This shrinking was inhibited by ruthenium red or CBX when they were added in combination with the capsaicin (Fig. 1). We could not completely rule out the involvement of connexin hemichannels because the blockers used in our protocol do not exhibit strict pharmacological specificity. However, if connexin hemichannels were involved in this phenomenon, cell shrinkage would be expected to occur throughout the cell membrane rather than only at the apical side.

Although we were not able to definitively determine the role of pannexin-1, these results are consistent with our hypothesis described above. One possible explanation for these results is that the pannexin-1 channel is involved in release of the anionic form of ATP, $\mathrm{ATP}^{-}$, together with $\mathrm{H}_{2} \mathrm{O}$ efflux to the extracellular space on the apical side of the cell under low-PCFL conditions, because the apical side is more exposed to mechanical stress on the nasal mucosa (Fig. 2).

In conclusion, we believe that pannexin-1 channelmediated ATP release has a distinct role in MCC from

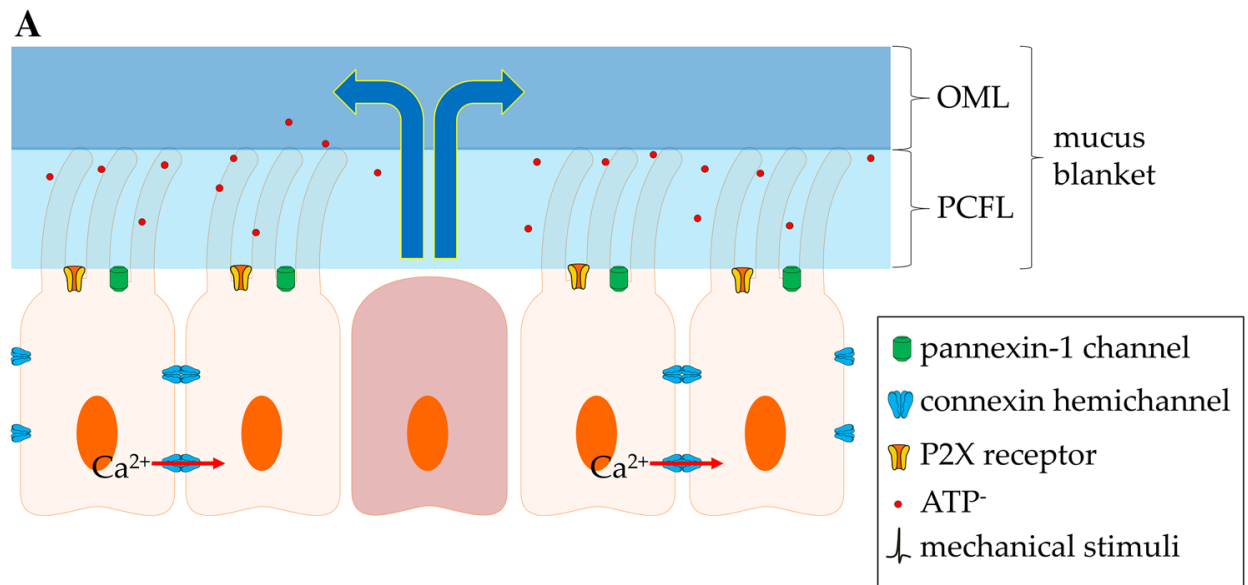

B

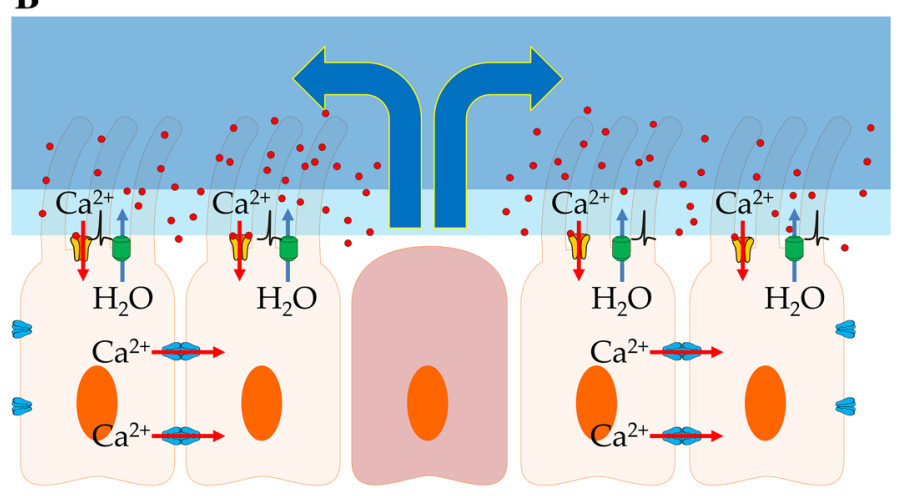

Fig. 2 Schematic of our hypothesized relationship between the mucus blanket components and $\mathrm{ATP}^{-} / \mathrm{H}_{2} \mathrm{O}$ efflux. a Under normal conditions, the gel-like outer mucus is appropriately secreted by goblet cells (the central cell in the figure) and submucosal glands. Liquid periciliary fluid is also maintained at moderate levels. Together, these allow efficient removal of inhaled particulate matter along with secreted mucus. b In pathological conditions such as infection and inflammation, the outer mucus is produced and secreted in excess fol- lowed by a decrease of periciliary fluid. The changes in osmolality and viscosity cause cell membrane stretching, leading to mechanical stimulation that induces pannexin-1 opening. Anionic ATP $^{-}$would then be released via the pannexin- 1 channel into the periciliary fluid layer, along with $\mathrm{H}_{2} \mathrm{O}$ that would increase the volume of the periciliary fluid. The released ATP could activate purinergic receptors, and ciliary movement would improve 
that of connexin channels and hemichannels. Synergetic effects of the pannexin-1 channel and the connexin channel could be the key molecular factors in the regulatory mechanism of the upper airway function. Modulation of these molecules may open a novel therapeutic strategy in the management of upper respiratory disorders.

Acknowledgements This work was supported in part by a Grant-in-Aid for Young Scientists (B) (No. 17K16950) to TO from the Japan Society for the Promotion of Science (JSPS), and by a UOEH Research Grant for the Promotion of Occupational Health to TO.

Author contributions TO designed and performed the research, coordinated the study, participated in data collection, and wrote the paper together with HS.

\section{Compliance with ethical standards}

All experiments were performed in accordance with the guidelines of the Ethics Committee of Animal Care and Experimentation, University of Occupational and Environmental Health (UOEH). All field methods were performed in accordance with procedures that were approved by the Laboratory Animal Research Center, UOEH, JAPAN, 2016 Sixth Edition (Assignment Numbers: LA16-12 for TO and LA16-52 for HS).

Conflict of interest No potential conflicts of interest were disclosed.

Open Access This article is distributed under the terms of the Creative Commons Attribution 4.0 International License (http://creativeco mmons.org/licenses/by/4.0/), which permits unrestricted use, distribution, and reproduction in any medium, provided you give appropriate credit to the original author(s) and the source, provide a link to the Creative Commons license, and indicate if changes were made.

\section{References}

1. Majima Y, Sakakura Y (1995) Mucociliary clearance in chronic sinusitis and allergic rhinitis. In: Tos M, Thomsen J, Baller V (eds) Rhinology-state of the art. Kugler, Amsterdam

2. Meda P, Haefliger JA (2016) Connexins and pannexins: from biology towards clinical targets. Swiss Med Wkly 146:w14365

3. Kim R, Chang G, Hu R, Phillips A, Douglas R (2016) Connexin gap junction channels and chronic rhinosinusitis. Int Forum Allergy Rhinol 6:611-617

4. BuSaba NY, Cunningham MJ (2008) Connexin 26 and 30 genes mutations in patients with chronic rhinosinusitis. Laryngoscope $118: 310-313$

5. Sedaghat AR, Cunningham MJ, Busaba NY (2014) Connexin 32 and 43 mutations: do they play a role in chronic rhinosinusitis? Am J Otolaryngol 35:33-36

6. Rash JE, Davidson KG, Kamasawa N, Yasumura T, Kamasawa M, Zhang C, Michaels R, Restrepo D, Ottersen OP, Olson CO, Nagy JI (2005) Ultrastructural localization of connexins (Cx36, Cx43, Cx45), glutamate receptors and aquaporin-4 in rodent olfactory mucosa, olfactory nerve and olfactory bulb. J Neurocytol 34:307-341

7. Yeh TH, Su MC, Hsu CJ, Chen YH, Lee SY (2003) Epithelial cells of nasal mucosa express functional gap junctions of connexin 43. Acta Otolaryngol 123:314-320
8. Locovei S, Wang J, Dahl G (2006) Activation of pannexin 1 channels by ATP through P2Y receptors and by cytoplasmic calcium. FEBS Lett 580:239-244

9. Chen B, Shaari J, Claire SE, Palmer JN, Chiu AG, Kennedy DW, Cohen NA (2006) Altered sinonasal ciliary dynamics in chronic rhinosinusitis. Am J Rhinol 20:325-329

10. Zhao KQ, Cowan AT, Lee RJ, Goldstein N, Droguett K, Chen B, Zheng C, Villalon M, Palmer JN, Kreindler JL, Cohen NA (2012) Molecular modulation of airway epithelial ciliary response to sneezing. FASEB J 26:3178-3187

11. Bruzzone R, Hormuzdi SG, Barbe MT, Herb A, Monyer H (2003) Pannexins, a family of gap junction proteins expressed in brain. Proc Natl Acad Sci USA 100:13644-13649

12. MacVicar BA, Thompson RJ (2010) Non-junction functions of pannexin-1 channels. Trends Neurosci 33:93-102

13. Ransford GA, Fregien N, Qiu F, Dahl G, Conner GE, Salathe M (2009) Pannexin 1 contributes to ATP release in airway epithelia. Am J Respir Cell Mol Biol 41:525-534

14. Sosinsky GE, Boassa D, Dermietzel R, Duffy HS, Laird DW, MacVicar B, Naus CC, Penuela S, Scemes E, Spray DC, Thompson RJ, Zhao HB, Dahl G (2011) Pannexin channels are not gap junction hemichannels. Channels 5:193-197

15. Yen MR, Saier MHJr (2007) Gap junctional proteins of animals: the innexin/pannexin superfamily. Prog Biophys Mol Biol 94:5-14

16. Praetorius HA, Leipziger J (2009) ATP release from non-excitable cells. Purinergic Signal 5:433-446

17. Boassa D, Ambrosi C, Qiu F, Dahl G, Gaietta G, Sosinsky G (2007) Pannexin 1 channels contain a glycosylation site that targets the hexamer to the plasma membrane. J Biol Chem 282:31733-31743

18. Ambrosi C, Gassmann O, Pranskevich JN, Boassa D, Smock A, Wang J, Dahl G, Steinem C, Sosinsky GE (2010) Pannexin 1 and pannexin 2 channels show quaternary similarities to connexons and different oligomerization numbers from each other. J Biol Chem 285:24420-24431

19. Ohbuchi T, Hohchi N, Ohkubo J, Hashida K, Koizumi H, Wakasugi T, Takenaga F, Suzuki H (2013) Identification of pannexins in rat nasal mucosa. Allergy Rhinol 4:e63-e65

20. Ohbuchi T, Takenaga F, Hohchi N, Wakasugi T, Ueta Y, Suzuki $\mathrm{H}$ (2014) Possible contribution of pannexin-1 to ATP release in human upper airway epithelia. Physiol Rep 2:e00227

21. Koizumi H, Ikezaki S, Ohbuchi T, Do BH, Hohchi N, Kawaguchi R, Kitamura T, Suzuki H (2017) Acetylcholine-induced ex vivo ATP release from the human nasal mucosa. Auris Nasus Larynx 44:422-427

22. Ohbuchi T, Do BH, Koizumi H, Takeuchi S, Ueta Y, Suzuki H (2017) Possible contribution of pannexin-1 to capsaicin-induced ATP release in rat nasal columnar epithelial cells. Channels 11:273-280

23. Iglesias R, Locovei S, Roque A, Alberto AP, Dahl G, Spray DC, Scemes E (2008) P2 $\times 7$ receptor-pannexin 1 complex: pharmacology and signaling. Am J Physiol Cell Physiol 295:C752-C760

24. Bao L, Locovei S, Dahl G (2004) Pannexin membrane channels are mechanosensitive conduits for ATP. FEBS Lett 572:65-68

25. Okada SF, Nicholas RA, Kreda SM, Lazarowski ER, Boucher RC (2006) Physiological regulation of ATP release at the apical surface of human airway epithelia. J Biol Chem 281:22992-23002

26. Dahl G (2015) ATP release through pannexon channels. Philos Trans R Soc Lond B Biol Sci 370:20140191

27. Lucas AM, Douglas LC (1934) Principles underlying ciliary activity in the respiratory tract. II. A comparison of nasal clearance in man, monkey and other mammals. Acta Otolaryngol 20:518-541

28. Bruzzone R, Barbe MT, Jacob NJ, Monyer H (2005) Pharmacological properties of homomeric and heteromeric pannexin 
hemichannels expressed in Xenopus oocytes. J Neurochem 92:1033-1043

29. Ma W, Hui H, Pelegrin P, Surprenant A (2009) Pharmacological characterization of pannexin-1 currents expressed in mammalian cells. J Pharmacol Exp Ther 328:409-418 